\title{
Studies on the Mycolic Acids from the Walls of Mycobacterium microti
}

\author{
By L. A. DAVIDSON, ${ }^{1}$ P. DRAPER ${ }^{1 *}$ AND D. E. MINNIKIN ${ }^{2}$ \\ ${ }^{1}$ National Institute for Medical Research, The Ridgeway, Mill Hill, London NW7 1AA, U.K. \\ ${ }^{2}$ Department of Organic Chemistry, The University, Newcastle-upon-Tyne NE1 7RU, U.K.
}

(Received 11 August 1981)

\begin{abstract}
Mycobacterium microti walls contained three types of mycolic acids, very similar to those found in Mycobacterium tuberculosis. An a-mycolate with two cyclopropane rings, a methoxymycolate with one cyclopropane ring and a methoxyl group, and a ketomycolate with one cyclopropane ring and a keto group were partially characterized. The mycolates made up $34 \%$ (by weight) of the peptidoglycan-arabinogalactan-mycolate wall skeleton. Young exponential phase cultures and organisms harvested from mouse lungs contained high proportions of ketomycolates; older cultures had roughly equal proportions of keto- and methoxymycolates. The proportion of $\alpha$-mycolates increased slightly with age of culture, but was always less than one-third of the total.
\end{abstract}

\section{INTRODUCTION}

Mycobacterium microti closely resembles Mycobacterium tuberculosis (Stanford \& Grange, 1974). Since $M$. microti is pathogenic to rodents, but not man, it is valuable as a laboratory model in place of $M$. tuberculosis. Mycolic acids are 2-branched, 3-hydroxy fatty acids produced by mycobacteria and related organisms (Minnikin \& Goodfellow, 1980). They mostly occur esterified to arabinose residues in the peptidoglycan-arabinogalactanmycolate wall skeleton but are also found in some solvent-extractable lipids such as trehalose 6,6'-dimycolate (Lederer et al., 1975; Asselineau \& Asselineau, 1978). Although the mycolic acids of $M$. tuberculosis have been studied extensively (Etemadi, 1967; Minnikin \& Polgar, 1966, 1967a, b; Asselineau et al., 1969; Gensler \& Marshall, 1977; Qureshi et al., 1978), nothing is known about $M$. microti mycolic acids. We have therefore investigated the composition of the mycolic acids from walls of $M$. microti and have also studied variations in the proportions of individual mycolate species during growth.

\section{METHODS}

The media in which $M$. microti OV248 was grown were based on those of Ungar et al. (1962). In the glycerol-free medium, glutamine, L-asparagine and Triton WR1339 were omitted, but monosodium glutamate $\left(8.0 \mathrm{~g}^{-1}\right)$ and Tween $80\left(0.5 \mathrm{ml}^{-1}\right)$ were added. In the modified Sauton medium, L-asparagine, citric acid, and Triton WR 1339 were omitted, but monosodium glutamate $\left(4.0 \mathrm{~g}^{-1}\right)$ and Tween $80\left(0.5 \mathrm{ml} 1^{-1}\right)$ were added. The pH of both media was adjusted with $\mathrm{NaOH}$ or $\mathrm{HCl}$ and the media were then autoclaved at $121^{\circ} \mathrm{C}$ for $20 \mathrm{~min}$. Bovine serum albumin (plasma fraction V; Armour \& Co., Eastbourne, U.K.) solution, sterilized by filtration, was added to the sterilized media to give a concentration of $5.0 \mathrm{~g} \mathrm{l}^{-1}$ in each medium.

Mycobacterium microti was grown in 5-litre flasks on glycerol-free medium, $\mathrm{pH} 7.0$. These cultures were grown for 15-18 d to an $A_{450}$ of 0.7-0.9. Variations in the relative proportions of mycolates during growth were studied using several series of $200 \mathrm{ml}$ cultures in 1-litre flasks. Bacilli were collected from cultures by centrifugation at $10000 \mathrm{~g}$ for $10 \mathrm{~min}$, washed twice with $0.05 \%(\mathrm{w} / \mathrm{v})$ Tween 80 , and freeze-dried. 
Mycobacterium microti was also grown in mice (CBA strain). The mice were injected intravenously with $0.4 \mathrm{mg}$ (approximate wet wt) of $M$. microti. After 8-10 weeks, the mice were killed and the bacilli were isolated from their lungs (Draper, 1971).

Preparation of methyl mycolates. Walls were prepared from freeze-dried bacilli by the method of Draper (1971); however, they were broken in suspension (about $5 \mathrm{mg} \mathrm{ml}^{-1}$ ) in $0.1 \mathrm{M}-\mathrm{Tris} / \mathrm{HCl}, \mathrm{pH} 7.2$, containing $0.05 \%(\mathrm{w} / \mathrm{v}$ ) Tween 80 with an MSE $150 \mathrm{~W}, 20 \mathrm{KHz}$ ultrasonic generator using a probe with a $2.8 \mathrm{~cm}^{2}$ cross-section and a probe displacement of $8 \mu \mathrm{m}$ for $20 \mathrm{~min}$. Freeze-dried bacilli or walls were extracted for $24 \mathrm{~h}$ with chloroform/methanol $(1: 1, \mathrm{v} / \mathrm{v})$ and methyl mycolates were produced by treating the whole defatted bacterial residue with methanol/toluene/concentrated $\mathrm{H}_{2} \mathrm{SO}_{4}\left(10: 10: 0.4\right.$, by vol.) at $50{ }^{\circ} \mathrm{C}$ (Minnikin et al., 1975). Methyl mycolates were prepared from chloroform/methanol-extracted walls (wall skeletons) of $M$. microti by treatment with $0.5 \%(\mathrm{w} / \mathrm{v}) \mathrm{KOH}$ in methanol at $37^{\circ} \mathrm{C}$ for $4 \mathrm{~d}$. The methyl mycolates were extracted into chloroform/methanol $(2: 1, \mathrm{v} / \mathrm{v})$.

Thin-layer chromatography (t.l.c.). Methyl mycolates were fractionated on silica gel 60 plates (Merck) by developing six times with petroleum spirit (b.p. $\left.40-60^{\circ} \mathrm{C}\right) /$ diethyl ether $(95: 5, \mathrm{v} / \mathrm{v})$. Methyl mycolates were detected on preparative thin-layer chromatograms by exposure to iodine vapour or on quantitative chromatograms by spraying with $0.5 \%(\mathrm{w} / \mathrm{v}) \mathrm{K}_{2} \mathrm{Cr}_{2} \mathrm{O}_{7}$ in $10 \%(\mathrm{v} / \mathrm{v}) \mathrm{H}_{2} \mathrm{SO}_{4}$ and charring at $150^{\circ} \mathrm{C}$ (Minnikin et al., 1975). The intensity of charring was measured with a double-beam recording microdensitometer (model EL2, MK IIIB; Joyce-Loebl \& Co., Gateshead, U.K.).

Infrared spectroscopy. Infrared (i.r.) spectra of samples as films on rock salt discs were recorded using a Perkin-Elmer 457 spectrometer.

Nuclear magnetic resonance spectroscopy. Nuclear magnetic resonance (n.m.r.) spectra of samples dissolved in $\mathrm{C}^{2} \mathrm{HCl}_{3}$ were recorded using a Varian EM-360 spectrometer with $\mathrm{C}^{1} \mathrm{HCl}_{3}$ as the internal standard.

Mass spectroscopy. Mass spectra were recorded using an AEI MS 9 instrument with a direct insertion probe, an ionizing voltage of $70 \mathrm{eV}$, and a temperature range of $230-250^{\circ} \mathrm{C}$.

\section{RESULTSAND DISCUSSION}

Mycolates made up about $34 \%$, by weight, of the wall skeleton of $M$. microti from glycerol-free medium, $\mathrm{pH}$ 7.0. The mycolic acid methyl esters from both isolated walls and defatted cells of $M$. microti were separated by t.l.c. into three components having the same mobilities as those of a sample of mycolic esters from $M$. tuberculosis (Minnikin \& Polgar, $1967 a, b)$. The least polar mycolates from $M$. tuberculosis are considered to have the general structure (I) (Minnikin \& Polgar, 1967a). Having no oxygen functions other than the 3-hydroxy ester unit, they fall into the class of the so-called $\alpha$-mycolates (Etémadi, 1967). The mycolates from $M$. tuberculosis having intermediate and greatest polarities have been found to be methoxy- and ketomycolates with the general structures (II) and (III), respectively (Minnikin \& Polgar, 1967 b). It is probable, therefore, that the mycolates from $M$. microti have related structures, and for the purposes of discussion they will now be described as $\alpha$-, methoxy- and ketomycolates. Samples $(40-60 \mathrm{mg})$ of each mycolic ester from $M$. microti were obtained by preparative t.l.c.

Each $M$. microti mycolate had i.r. absorbances at $1025 \mathrm{~cm}^{-1}$ and $3060 \mathrm{~cm}^{-1}$, attributable to cyclopropane rings (Cole, 1954). The n.m.r. spectra of the methoxymycolates had resonances at $\delta 3.0\left(1 \mathrm{H}\right.$, broad) due to $\mathrm{CHOCH}_{3}$ and $\delta 3.34\left(3 \mathrm{H}\right.$, singlet) due to $\mathrm{CHOCH}_{3}$, and the ketomycolate had a resonance at $\delta 1.07$ (3H, doublet) due to $\mathrm{CH}_{3} \mathrm{CHCO}$. All three mycolates had broad resonances at $\delta-0.3$ and $\delta+0.6(2 \mathrm{H}$ and $6 \mathrm{H}$ for $\alpha, 0.7 \mathrm{H}$ and $2.1 \mathrm{H}$ for methoxy, $0.8 \mathrm{H}$ and $2.4 \mathrm{H}$ for keto), attributable to 1,3 -disubstituted cis-cyclopropane rings; the methoxy- and ketomycolate n.m.r. spectra also showed broad resonances at $\delta 0.2(1.2 \mathrm{H}$ for methoxy, $0.8 \mathrm{H}$ for keto) due to 1,2 -disubstituted trans-cyclopropane rings (Minnikin, 1966; Longone \& Miller, 1967). For the $M$. microti methoxy- and ketomycolate cyclopropane rings, the cis to trans ratios were estimated to be $7: 3$ and $4: 1$, respectively, compared with $5: 1$ and $1: 2$ in the corresponding mycolates in M. tuberculosis (Minnikin \& Polgar, $1967 a, b)$. In $M$. tuberculosis $\alpha$-mycolate, as in $M$. microti $\alpha$-mycolate, only cis-cyclopropane rings were present. The ratio differences in corresponding mycolates from $M$. microti and $M$. tuberculosis may reflect a species difference or be due to differences in culture conditions. 
Mycobacterial methyl mycolates pyrolyse during mass spectrometry (Etémadi, 1967):<smiles>[R]COC(=O)C([R])C([R])OO</smiles>

Methyl mycolate<smiles>[R]C=C(O)OCCOC(=O)C[R]</smiles>

Straight-chain methyl ester

Peaks from the pyrolysis products predominated in the mass spectra. Mass spectra of $M$. microti methyl mycolates were quite similar to those of the corresponding compounds from M. tuberculosis (Minnikin \& Polgar, 1966, 1967a, b). In both cases, the major straight-chain ester produced was methyl hexacosanoate $(m / e 410)$. The spectrum of $M$. microti methyl $\alpha$-mycolate had a single series of meroaldehyde peaks, $m / e 712,740,768,796,824,852$ (the major component is italicized), and a series $m / e 459,487,515,543$, due to fragmentation of the meroaldehydes. Similar series of peaks were present in the mass spectra of $M$. tuberculosis methyl $\alpha$-mycolates (Etémadi \& Lederer, 1965; Minnikin \& Polgar, 1966, 1967 a; Asselineau et al., 1969; Qureshi et al., 1978). We suggest that $M$. microti methyl $\alpha$-mycolates are a single homologous series (structure I) with $x+y+z=42,44,46,48,50,52$. The $M$. microti methyl methoxymycolate spectrum had a major series of peaks, $m / e 740,768,796,824,852$, 880 , due to meroaldehyde $-\mathrm{CH}_{3} \mathrm{OH}$. Two series $(\mathrm{m} / \mathrm{e} 519,547,575,603,631$, and 297 , 325) were due to meroaldehyde cleavage adjacent to the methoxyl group. Loss of $\mathrm{CH}_{3} \mathrm{OH}$ from the first of these two series gave another major series. These results, in conjunction with those reported for $M$. tuberculosis (Minnikin \& Polgar, 1967b), indicate that the major series of $M$. microti methyl methoxymycolates has structure II a with $y+z=27,29,31,33,35,37$.

I<smiles>CCCCCCCCCC(O)CCC1CC(CCCC)C1</smiles>

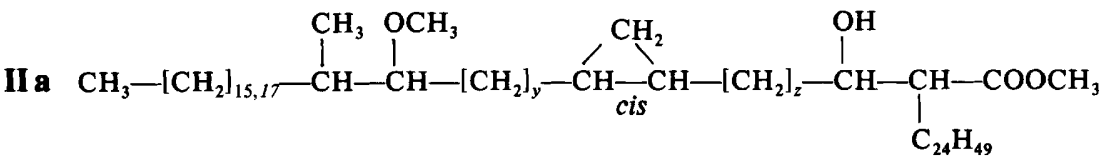<smiles>CCCCCCCCCCC(C)C(C)CCCCCCC(O)C(CC)C(=O)OC</smiles><smiles>CCCC(C)C(=O)OCC1CC(CCC(O)C(CC)C(=O)OC)C1</smiles>

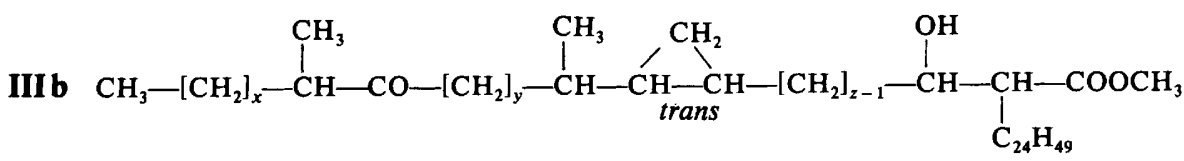




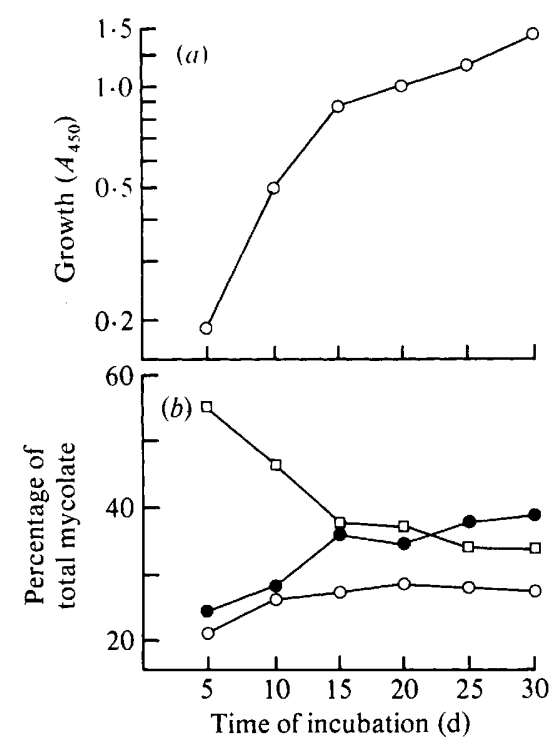

Fig. 1. (a) Growth of $M$. microti OV248 in glycerol-free medium, $\mathrm{pH} 7 \cdot 0$. (b) Variations during growth in the relative amounts of bound mycolates: $a$-mycolate $(O)$, methoxymycolate $(O)$ and ketomycolate (口).

A minor series of peaks $(m / e 782,810,838,866)$ was probably due to meroaldehyde $\mathrm{CH}_{3} \mathrm{OH}$ ions from a minor homologous series (structure IIb) with $y+z=29,31,33,35$, as in $M$. tuberculosis (Minnikin \& Polgar, 1967b). The $M$. microti methyl ketomycolate mass spectrum had two series of meroaldehyde peaks similar to those found in the spectrum of the ketomycolate from $M$. tuberculosis (Minnikin \& Polgar, 1967 b): the major one $(\mathrm{m} / \mathrm{e} \mathrm{812}$, $840,868,896)$ and the minor one $(m / e 826,854,882,910)$. The overall structures of $M$. microti methyl ketomycolates are possibly similar to those of $M$. tuberculosis (III a and III b) with $x+y+z=48,50,52,54$. The major series (III b) in $M$. tuberculosis is the minor series in $M$. microti; this correlated with the n.m.r. results, which showed that cis-cyclopropane groups are more abundant in $M$. microti ketomycolates, but trans are more abundant in $M$. tuberculosis ketomycolates.

During the period of approximately exponential growth (5-15 d) in glycerol-free medium at $\mathrm{pH} 7.0$ (Fig. 1a) the initially high proportion of ketomycolate decreased rapidly, with a somewhat smaller increase in methoxymycolate (Fig. $1 b$ ). The proportion of $\alpha$-mycolate also showed an increase during the same period but as the rate of growth slowed down (15-30 d) the proportion of this component became fairly constant (Fig. 1). Similar changes in the relative proportions of mycolates occurred in $M$. microti grown in modified Sauton medium, $\mathrm{pH} 7.0$. Since the $\mathrm{pH}$ of cultures increased by over one unit during growth, $M$. microti was grown in glycerol-free media with initial $\mathrm{pH}$ values of 6.0 and 8.0 ; these cultures grew more slowly than those initially at $\mathrm{pH} 7.0$. However, at both $\mathrm{pH} 6.0$ and 8.0 , the changes occurring in the relative proportions of the three types of mycolates were similar to those which occurred in cultures at $\mathrm{pH} \mathrm{7.0}$. At $\mathrm{pH} 6.0$ and 8.0, respectively, the proportion of $\alpha$-mycolate rose from $20 \%$ to $30 \%$ and from $14 \%$ to $27 \%$. That of methoxymycolate rose from $14 \%$ to $25 \%$ and from $28 \%$ to $43 \%$. In ketomycolate it fell from $66 \%$ to $45 \%$ and from $58 \%$ to $30 \%$. Wall skeletons of $M$. microti from mouse lungs (two batches) had $\alpha$ :methoxy : ketomycolate ratios of $33: 22: 45$ and $34: 25: 41$.

The most striking change in the mycolic acid composition during growth is the apparent replacement of high proportions of ketomycolates in exponential phase cultures by methoxymycolates as stationary phase is approached (Fig. 1). Methoxymycolates are 
considered to be synthesized from ketomycolates or their precursors, the methyl group being provided by methionine (Gastambide-Odier et al., 1964). Alkylations involving a single carbon unit from methionine also are involved in the conversion of long-chain cisoctadecenoic acids either to methyl-branched acids such as tuberculostearic (10methyloctadecanoic) acid or cyclopropane acids such as lactobacillic $(11,12$ methyleneoctadecanoic) acid (Lederer, 1969). It is very interesting to note that both tuberculostearic and lactobacillic acids tended to accumulate with age in the organisms producing them (for a review see Lechevalier, 1977). An explanation of this phenomenon may be that in resting cells relatively reactive cis double bonds are replaced by chemically more inert methyl branches and cyclopropane rings. It is possible that the conversion of the keto function in the mycolates of $M$. microti to a less reactive methoxy group is an analogous mechanism for the maintenance of envelope integrity in resting cells. $M$. microti obtained from mouse lungs, in containing considerably more ketomycolate than methoxymycolate, corresponds more closely in mycolic acid composition to actively growing exponential phase than to stationary phase cultures grown in vitro (Fig. 1).

Quantitative studies of variation in mycolic acid composition with growth conditions have not been widely reported. Michalec \& Mára (1975) recorded variations in the proportions of two main unidentified components in Mycobacterium bovis BCG depending on origin and repeated lyophilization. An increase in growth temperature was shown by Toriyama et al. $(1978,1980)$ to lead to an increase in average chain length for the mycolates of Mycobacterium phlei.

\section{REFERENCES}

Asselineau, C. \& Asselineau, J. (1978). Trehalosecontaining glycolipids. Progress in the Chemistry of Fats and Other Lipids 16, 59-99.

asselineau, C., Montrozier, H. \& Promé, J. C. (1969). Structure des acides $\alpha$-mycoliques isolés de la souche humaine Cannetti de Mycobacterium tuberculosis. Bulletin de la Société chimique de France, 592-596.

Cole, A. R. H. (1954). Infra-red spectra of natural products. Part II. Compounds containing the cyclopropane ring. Journal of the Chemical Society, 3807-3812.

DrAPER, P. (1971). The walls of Mycobacterium lepraemurium: chemistry and ultrastructure. Journal of General Microbiology 69, 313-324.

ETÉmAdI, A. H. (1967). Les acides mycoliques; structure, biogenèse et intérêt phylogénétique. Exposés annuels de biochimie médicale 28, 77-109.

EtÉmAdi, A. H. \& Lederer, E. (1965). Sur la structure des acides $\alpha$-mycoliques de la souche humaine 'Test' de Mycobacterium tuberculosis. Bulletin de la Société chimique de France, 26402645.

Gastambide-Odier, M., Delaumeny, J.-M. \& Lederer, E. (1964). Mise en évidence de cycles propaniques dans divers acides mycoliques de souches humaines et bovines de Mycobacterium tuberculosis. Compte rendu hebdomadaire des séances de l'Académie des sciences 259, 3404-3407.

Gensler, W. J. \& Marshall, J. P. (1977). Structure of mycobacterial bis-cyclopropane mycolates by mass spectrometry. Chemistry and Physics of Lipids 19, 128-143.

LeCheVAliER, M. P. (1977). Lipids in bacterial taxonomy - a taxonomist's viewpoint. CRC Critical Reviews in Microbiology 5(2), 109-210.
LEDERER, E. (1969). Some problems concerning biological C-alkylation reactions and phytosterol biosynthesis. Quarterly Review, Chemical Society 23, 453-481.

Lederer, E., Adam, A., Ciorbaru, R., Petit, J.-F. \& WIETZERBIN, J. (1975). Cell walls of mycobacteria and related organisms: chemistry and immunostimulant properties. Molecular and Cellular Biochemistry 7, 87-104.

LONGONE, D. T. \& MilleR, A. H. (1967). Shielding effects in substituted cyclopropanes. Chemical Communications, 447-448.

Michalec, C. \& MÁrA, M. (1975). Thin-layer chromatography of mycolic acids and its application for the characterization of BCG strains. Journal of Hygiene, Epidemiology, Microbiology and Immunology 19, 467-470.

MinNikin, D. E. (1966). Nuclear magnetic resonance spectra of long-chain 1,2-disubstituted cyclopropane esters. Chemistry and Industry, 2167.

Minnikin, D. E. \& Goodfellow, M. (1980). Lipid composition in the classification and identification of acid-fast bacteria. In Microbiological Classification and Identification, pp. 189-256. Edited by $M$. Goodfellow \& R. G. Board. London: Academic Press.

Minnikin, D. E. \& Polgar, N. (1966). Studies on the mycolic acids from human tubercle bacilli. Tetrahedron Letters, 2643-2647.

Minnikin, D. E. \& Polgar, N. (1967a). The mycolic acids from human and avian tubercle bacilli. Chemical Communications, 916-918.

Minnikin, D. E. \& PolgaR, N. $(1967 b)$. The methoxymycolic and ketomycolic acids from human tubercle bacilli. Chemical Communications, 11721174. 
Minnikin, D. E., Alshamaony, L. \& Goodfellow, M. (1975). Differentiation of Mycobacterium, Nocardia, and related taxa by thin-layer chromatographic analysis of whole-organism methanolysates. Journal of General Microbiology 88, 202-204.

Qureshi, N., TAKAYAMA, K., JoRdi, H. C. \& SCHNOES, H. K. (1978). Characterization of the purified components of a new homologous series of a-mycolic acids from Mycobacterium tuberculosis H37Ra. Journal of Biological Chemistry 253, 5411-5417.

Stanford, J. L. \& Grange, J. M. (1974). The meaning and structure of species as applied to mycobacteria. Tubercule 55, 143-152.

Toriyama, S., Yano, I., Masui, M., Kusunose, M. \&
Kusunose, E. (1978). Separation of $\mathrm{C}_{50-60}$ and $\mathrm{C}_{70-80}$ mycolic acid molecular species and their changes by growth temperatures in Mycobacterium phlei. FEBS Letters 95, 111-115.

Toriyama, S., Yano, I., Masui, M., Kusunose, E., Kusunose, M. \& AKImORI, N. (1980). Regulation of cell wall mycolic acid biosynthesis in acid-fast bacteria. I. Temperature-induced changes in mycolic acid molecular species and related compounds in Mycobacterium phlei. Journal of Biochemistry 88, 211-221.

Ungar, J., Muggleton, P. W., Dudley, J. A. R. \& GRIFFITHS, M. I. (1962). Preparation and properties of a freeze-dried BCG vaccine of increased stability. British Medical Journal, pt 2, 1086-1089. 